\title{
Can a native rodent species limit the invasive potential of a non-native rodent species in tropical agroforest habitats?
}

Article

Accepted Version

Stuart, A. M., Prescott, C. V. and Singleton, G. R. (2016) Can a native rodent species limit the invasive potential of a nonnative rodent species in tropical agroforest habitats? Pest Management Science, 72 (6). pp. 1168-1177. ISSN 1526-4998 doi: https://doi.org/10.1002/ps.4095 Available at https://centaur.reading.ac.uk/41538/

It is advisable to refer to the publisher's version if you intend to cite from the work. See Guidance on citing.

Published version at: http://onlinelibrary.wiley.com/doi/10.1002/ps.4095/abstract

To link to this article DOI: http://dx.doi.org/10.1002/ps.4095

Publisher: Wiley

All outputs in CentAUR are protected by Intellectual Property Rights law, including copyright law. Copyright and IPR is retained by the creators or other copyright holders. Terms and conditions for use of this material are defined in the End User Agreement.

www.reading.ac.uk/centaur 
Central Archive at the University of Reading

Reading's research outputs online 
Can a native rodent species limit the invasive potential of a non-native rodent species in tropical agroforest habitats?

Alexander M. Stuart ${ }^{\mathrm{a}, \mathrm{b}}$, Colin V. Prescott ${ }^{\mathrm{b}}$ and Grant R. Singleton ${ }^{\mathrm{a}}$

${ }^{\mathrm{a} C}$ Crop and Environmental Sciences Division, International Rice Research Institute, DAPO Box 7777 Metro Manila, Philippines.

${ }^{\mathrm{b}}$ School of Biological Sciences, The University of Reading, Berkshire, RG6 6AS, UK.

\section{Corresponding author:}

Alexander M. Stuart, International Rice Research Institute, DAPO Box 7777 Metro Manila, Philippines. Email: a.stuart@irri.org. Telephone: +63 495362701 ext 2523.

This article has been accepted for publication and undergone full peer review but has not been through the copyediting, typesetting, pagination and proofreading process, which may lead to differences between this version and the Version of Record. Please cite this article as doi: 10.1002/ps.4095

This article is protected by copyright. All rights reserved. 


\begin{abstract}
BACKGROUND: Little is known about native and non-native rodent species interactions in complex tropical agro-ecosystems. We hypothesised that the native non-pest rodent Rattus everetti may be competitively dominant over the invasive pest rodent Rattus tanezumi within agroforests. We tested this experimentally by using pulse removal for three consecutive months to reduce populations of $R$. everetti in agroforest habitat and assessed over 6-months the response of $R$. tanezumi and other rodent species.

RESULTS: Following removal, $R$. everetti individuals rapidly immigrated into removal sites. At the end of the study period, $R$. tanezumi were larger and there was a significant shift in their microhabitat use with respect to the use of ground vegetation cover following the perturbation of R. everetti. Irrespective of treatment, R. tanezumi selected microhabitat with less tree canopy cover, indicative of severely disturbed habitat, whereas, $R$. everetti selected microhabitat with a dense canopy.

CONCLUSION: Our results suggest that sustained habitat disturbance in agroforests favours $R$.

tanezumi, whilst the regeneration of agroforests towards a more natural state would favour native species and may reduce pest pressure in adjacent crops. In addition, the rapid recolonisation of $R$. everetti suggests this species would be able to recover from non-target impacts of short-term rodent pest control.
\end{abstract}

\title{
Keywords
}

Interspecific competition, Microhabitat use, Pest management, Rattus everetti, Rattus tanezumi, Removal experiment

This article is protected by copyright. All rights reserved. 


\section{Introduction}

Rodentia is the most diverse group among mammals with over 2050 species described, of which many are endemic to large or remote oceanic islands. ${ }^{1,2}$ Oceanic islands, however, are often recognised for their vulnerability to non-native rodent invasions due to a lack of functionally equivalent competitors, mainly because of poor native rodent assemblages, as well as a lack of natural predators. ${ }^{3,4}$ On the other hand, oceanic islands that have high rodent endemism are more likely to have species that can successfully compete against invasive rodent species in natural ecosystems. ${ }^{5}$ However, there are few studies that have investigated interactions between native and non-native rodent species in invaded ecosystems ${ }^{6-8}$ In addition, anthropogenic activities, such as urbanisation, deforestation and agriculture, on oceanic islands with high rodent endemism have caused the degradation of many natural habitats, leading to both a decline in the abundance and diversity of endemic rodent species ${ }^{2,9}$ and an increase in the abundance of non-native pest rodent species that can cause severe crop losses and have devastating effects on native fauna. ${ }^{6,10}$ Nonnative rodent species also have been implicated in reducing the distribution and abundance of native small rodents due to competition for limited resources and the spread of new diseases. ${ }^{11}$

The Philippines is an oceanic archipelago recognised for its high rodent diversity and endemism, with over seventy murid rodent species described. ${ }^{2,12}$ The majority of endemic rodent species in the Philippines are restricted to habitats that experience minimal habitat disturbance,

such as natural forest ecosystems. ${ }^{9,}{ }^{12}$ None of these endemic rodents are considered to be pests, ${ }^{12,}$ ${ }^{13}$ whereas, the five rodent species considered pests, are considered to be non-native in origin, and generally inhabit highly disturbed areas. ${ }^{12}$ These species are Rattus tanezumi (Temminck), Rattus exulans (Peale), Rattus argentiventer (Robinson and Kloss), Rattus norvegicus (Berkenhout) and 
Mus musculus domesticus (Linnaeus); their occurrence and relative abundance appears to increase with increasing habitat disturbance, with few trapped in forests, even when adjacent to agricultural land. ${ }^{9,14-16}$ In complex agricultural landscapes that include habitats such as agroforest, grassland, riparian, and various agricultural crops, both native and non-native rodent species co-exist. ${ }^{13,17-19}$ These commonly include the endemic non-pest species, Rattus everetti (Gunther) (common Philippine forest rat) and Chrotomys mindorensis (Kellogg) (striped shrew-rat), and the invasive pest species, $R$. tanezumi and $R$. exulans. However, little is known about the interactions that take place between native and non-native rodent species in these habitats.

Recent studies on the interaction between native and invasive rodent species highlight that targeted manipulation of population densities or habitat could favor native species and provide a basis for minimising the negative impact of invasive species on agricultural production, ${ }^{11}$ human health ${ }^{12}$ or biodiversity. ${ }^{20}$ In eastern Australia, Stokes et al. ${ }^{5}$ reported that a native rodent, Rattus fuscipes, was able to suppress the invasive rodent, Rattus rattus, in disturbed forest habitat. In eastern Africa, Taylor et al. ${ }^{21}$ reported that the main agricultural rodent pest, Mastomys natalensis, was the dominant species in croplands when the small mammal community was sparse, whereas it was less common when the small mammal community was diverse. In response to these findings, Banks et al..$^{20}$ proposed that the reintroduction of a native rodent, $R$. fuscipes, following removal of $R$. rattus, could reduce the reinvasion success of $R$. rattus, at the urban-bushland interface, ${ }^{11}$ and lead to biodiversity benefits, and Taylor et al. ${ }^{21}$ suggest encouraging heterogeneous habitats on crop margins to favour a diverse native small mammal communities. Previous studies in the Philippines suggest that non-native pest species of rodents are restricted to heavily disturbed areas except where the diversity and abundance of native species are low. ${ }^{22-24}$ For example, in the lowland agro-ecosystems of the Sierra Madre Biodiversity Corridor, northern Luzon, $R$. tanezumi is the most abundant rodent species in a variety of agricultural habitats, including rice fields and 
coconut groves, where few native rodents are present. ${ }^{17,25}$ However, in agroforest ecosystems, a moderately disturbed hillside habitat comprised of coconut trees interspersed with other trees, the abundance of $R$. tanezumi is low, whereas the abundance of the larger native rodent $R$. everetti is high. ${ }^{17} R$. everetti is an ecological generalist that is tolerant of a wide variety of habitats and appears to prefer moderately disturbed habitat; ${ }^{9,15}$ thus, it may block or inhibit $R$. tanezumi from establishing within agroforest because of interspecific competition. ${ }^{15,17}$

$R$. tanezumi is a serious pest of rice and coconut in the Philippines, with reported rice yield losses of up to $50 \%$ in some regions of Luzon. ${ }^{26,27}$ In an effort to control rodent pests in the Philippines, farmers often apply rodenticides and periodically remove regenerating second growth vegetation that are perceived to provide refugia for pest rodents. The latter creates highly disturbed habitat that is considered to be less suitable for native non-pest rodents and more suitable for nonnative pest rodents. ${ }^{9,14,15}$ If $R$. everetti is competitively dominant over $R$. tanezumi in agroforest habitat, any form of control that has a negative effect on $R$. everetti populations may be counterproductive, resulting in an increase in the pest species.

We conducted a pulse perturbation experiment ${ }^{28}$ to assess the response of the rodent community following pulsed removal of $R$. everetti from an agroforest habitat. Interspecific competition is considered to have a negative effect on the fitness of individuals by effecting reproduction, growth and/or survival. ${ }^{29,30}$ We hypothesise that a reduction of the $R$. everetti population reduces competitive pressure on $R$. tanezumi, and we would expect a concomitant increase in the reproduction rates, growth rates and/or survival of $R$. tanezumi. Furthermore, if interference competition has been operating, we would expect an increase in abundance by immigration of $R$. tanezumi following removal of $R$. everetti individuals.

Differential resource selection is recognised as one of the principal relationships which permit species coexistence. ${ }^{31,32}$ Resources are considered to be selected when they are used in 
higher proportion to their availability. However, the habitat selected by an individual may not be its preferred choice if it is affected by intra- or interspecific competition, such as territoriality or competition for food. ${ }^{32}$ The agroforest ecosystem is comprised of a heterogenous vegetation structure. We assessed microhabitat use to determine whether the vegetation structure was a significant factor influencing $R$. tanezumi and $R$. everetti distribution within agroforest habitat and whether perturbation of $R$. everetti had an effect.

By removing $R$. everetti from agroforest populations, we are simulating a non-target impact of lethal rodent pest control on $R$. everetti, such as would likely result from rodenticide application in habitats adjacent to rice fields to target rodent pests of rice. We therefore investigated the population recovery of $R$. everetti in agro-ecosystems following short-term lethal control.

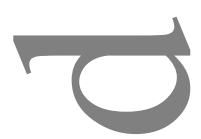

\section{Materials and methods}

\subsection{Study area}

The study was conducted in the Municipality of Baler, Aurora, Philippines $\left(15^{\circ} 73^{\prime} \mathrm{N} ; 121^{\circ} 56^{\prime} \mathrm{E}\right)$. Aurora province is located on the mid-eastern coast of Central Luzon (Region III), and covers the eastern portion of the Sierra Madre Mountain Range. Aurora has a land area of 324,000 hectares, of which, 230,000 hectares $(71 \%)$ is covered by forest. Thirty percent of Aurora is coastal flatland, where 50,000 ha are cultivated for agriculture. The forests occur mainly in mountainous areas that cover most of the province.

The study sites were located in coconut-based agroforest habitat, located on the lower slopes of hillsides, at an elevation of 30-70 m asl. The coconut trees were interspersed with small trees valued for timber and firewood, and perennial crops such as banana and citrus. There was a 
heterogenous vegetation structure with patches of open canopy and dense understorey vegetation. There was typically $25-75 \%$ canopy cover and $25-100 \%$ undergrowth vegetation cover. ${ }^{11}$ At higher elevation (45 - $100 \mathrm{~m}$ asl), above the agroforest habitat, secondary lowland forest was present. At low elevation ( $0-20 \mathrm{~m}$ asl), rice fields were located $25-130 \mathrm{~m}$ from the study sites. There are no distinct wet or dry seasons in the study area, with rainfall distributed more or less evenly throughout the year. The average monthly rainfall is $273.9 \mathrm{~mm}$, with extreme rainfall events most likely to occur between October and December. The annual average temperature is $25.3^{\circ} \mathrm{C}$, the warmest months are June and July and the coolest are January and February.

\subsection{Experimental design}

Four different sites situated in agroforest habitat were selected that were similar in vegetation structure. At each site, a trapping grid of $42(6 \times 7)$ locally-made single-capture live cage-traps ( $300 \times 140 \times 140 \mathrm{~mm})$ was set. Traps were spaced $15 \mathrm{~m}$ apart, giving a grid area of $6750 \mathrm{~m}^{2}$. The effective trapping area is expected to be larger than the actual grid area as animals are also attracted to traps from an area surrounding the trapping grid. ${ }^{29,33}$ Trapping sites were at least $500 \mathrm{~m}$ apart (no individual rodents were caught at more than one site).

Trapping was conducted monthly from May to October 2007. Traps were 'pre-baited' for three nights before the trapping session began. Traps were set for four consecutive nights. Traps were baited in the morning with coconut pieces combined with a live golden apple snail (Pomacea canaliculata Lamarck) to increase diversity of species captured. They were checked each morning beginning at dawn. Trapped animals were identified to species, sexed and individually marked with a combination of ear punches (see Stuart et al. ${ }^{17}$ for further details). Body measurements were recorded and female breeding condition was determined according to Aplin et al. ${ }^{34}$ 
Two treatment sites were randomly selected for $R$. everetti removal and there were two non-treatment sites for comparison. In the treatment sites, all $R$. everetti individuals trapped on the $1^{\text {st }}$ night were released to enable an estimate of population abundance using mark-recapture methods. On the $2^{\text {nd }}, 3^{\text {rd }}$ and $4^{\text {th }}$ nights, all $R$. everetti individuals were removed and euthanased. $R$. everetti removal trapping was conducted over the first three trapping sessions, each a month apart.

This was followed by three monthly sessions of non-removal trapping to estimate the recovery of R. everetti populations. During each month, all sites were trapped within a two-week period and the stage of the rice crop nearest each site was recorded.

To assess effectiveness of live-traps and to obtain an additional measure of abundance, kill-traps (break-back traps) were set in all sites during the final trapping session in October 2007, for an additional three nights immediately after live-trapping. Kill-traps were placed in the same location as live-traps and were baited with coconut only.

Traps occasionally went missing or were sprung by terrestrial hermit crabs (Coenobita sp.). These traps were excluded from the total number of traps nights.

\subsection{Microhabitat}

At each trap station, the vegetation structure ('microhabitat') was assessed by measuring the following physical features:

i. Ground vegetation cover - measured by visually estimating and averaging the percentage of a circular quadrat of one metre radius covered with vegetation less than $10 \mathrm{~cm}$ in height (such as grass, moss or leaf litter). The quadrat was centred on the trap entrance.

This article is protected by copyright. All rights reserved. 
ii. Understorey vegetation cover - measured by visually estimating and averaging the percentage of a quadrat of one metre radius covered with vegetation with a height between $10 \mathrm{~cm}$ and $2 \mathrm{~m}$ (such as shrubs and ferns).

iii. Canopy cover - measured by visually estimating and averaging the percentage canopy cover, from vegetation more than $2 \mathrm{~m}$ in height, above the trap.

iv. Understorey vegetation height - measured directly above the trap entrance.

Categories of percentage vegetation cover were: less than $25 \%, 25-49 \%, 50-74 \%$, and more than $74 \%$. The microhabitat at each trap station was measured during each trapping session by a single experimenter to avoid bias

\subsection{Analyses}

Statistical analyses were carried out using SPSS version 18 (SPSS Inc., Chicago, IL, USA). The mean number of individuals caught per trap grid for every 100 trap nights (excluding recaptures within trapping sessions) provided an index of the relative abundance of animals per trapping effort (no. caught per 100 trap nights). Linear mixed models with maximum likelihood estimation were used to analyse differences in relative abundance $(\ln Y+1)$ over time and between treatments for the three most commonly trapped species, $R$. everetti, C. mindorensis and $R$. tanezumi. Fixed effects entered into the model included month (as a repeated variable with diagonal repeated covariance), treatment, species and all interactions. Trapping sites were entered as random effects. Using $R$. everetti capture data, for which suitable mark-recapture data were available, R. everetti abundance estimates were verified using Huggins closed captures models in Program MARK ${ }^{35}$ that simultaneously incorporated mixture models and sex as a covariate to 
model heterogeneity in the data when estimating population size. ${ }^{36,37}$ For increased precision, data were pooled within treatments. Recapture rates for $R$. tanezumi and $C$. mindorensis were insufficient for mark recapture analyses.

R. tanezumi are known to migrate between rice fields and adjacent habitats at different crop stages, moving into the rice fields when there is sufficient cover provided by the mid-tillering crop and into adjacent habitats during land preparation, when the rice habitat is disturbed. ${ }^{37,38}$ To investigate whether the stage of the nearby rice crop influenced $R$. tanezumi abundance in agroforest habitat, linear mixed models of $R$. tanezumi abundance between treatments and crop stages was calculated; with crop stage categorised as either vegetative (seedling to tillering), generative (booting to ripening) or stubble (post-harvest) and trapping sites entered as random effects.

Low recapture rates of $R$. tanezumi and C. mindorensis precluded the analysis of growth and survival. Thus, indices of body condition were used to measure fitness. ${ }^{29,}{ }^{39}$ Indices of condition were constructed by estimating body condition based on a regression between skeletal size (head and body length) and body mass. ${ }^{40}$ The regression equations obtained by Stuart ${ }^{37}$ using a 18-month data set were used to calculate the index of condition for first captures and monthly recaptures of adult $R$. tanezumi $(\geq 140 \mathrm{~mm}), R$. everetti (females: $\geq 173 \mathrm{~mm}$, males: $\geq 180 \mathrm{~mm}$ ) and C. Mindorensis $(\geq 135 \mathrm{~mm}$ ). Adults were classified based on the head and body length below which $\leq 5 \%$ of females and $\leq 10 \%$ of males were sexually mature. ${ }^{37}$ Pregnant females were omitted.

Linear mixed models were used to analyse condition index and body size (head and body length) against month, treatment and sex. All interactions were included and trapping sites were included as random effects. Each species was analysed separately. To reduce variance, juvenile $R$. tanezumi and C. mindorensis were excluded from the analysis of body size due to low numbers of 
captures. Linear mixed models were also used to test for differences in the proportion of females captured between species, treatment and month. Binary logistic regression was used to investigate whether $R$. everetti removal influenced the occurrence of adult females in breeding condition. Independent variables entered into the model were treatment, trapping period (May; JuneOctober), site and the treatment $\mathrm{x}$ trapping period interaction. Trapping sessions from June to October were pooled due to low sample size. For the analysis of $R$. tanezumi, crop stage was included as a covariate.

To assess $R$. everetti and $R$. tanezumi 'microhabitat' selection and whether this was influenced by $R$. everetti removal, we performed binary logistic regression analysis of trap occupancy (presence; absence) in relation to vegetation cover. Logistic regression was used to model the resource selection probability function, i.e. the probability that a resource unit, i.e. vegetation cover, is used given census information on which units were used or available in the study area. ${ }^{32}$ Independant variables entered into the full model were month, trapping site, treatment, vegetation (understorey, ground, canopy) cover, treatment $\mathrm{x}$ vegetation cover and month $\mathrm{x}$ treatment $\mathrm{x}$ vegetation cover. Non-significant variables $(\mathrm{p}>0.05)$ were removed sequentially using the backward elimination technique ${ }^{41}$ and the significance of each variable was assessed by analysing the difference in the model log-likelihood statistic with and without the variable present. ${ }^{42}$ Univariate GLM was used to analyse the effect of mean vegetation height (square-root transformed) on trap occupancy (presence/absence). 


\section{Results}

During six sessions of live-trapping, from May to October 2007, and 3668 trap nights (excluding 364 trap nights due to missing or sprung traps with no capture), we captured $155 R$. everetti individuals (387 captures), $118 R$. tanezumi individuals (146 captures), 50 C. mindorensis individuals (118 captures), nine $R$. exulans individuals (12 captures), and five Bullimus luzonicus (Thomas) individuals (12 captures) (Table $\mathrm{S} 1$ ). During the removal trapping sessions, the $R$. everetti population in each treatment site was reduced by at least two thirds (Table 1). Aside from a few exceptions, the abundance estimates were in general agreement with the estimated population size calculated using Huggins closed captures models, indicating that $R$. everetti capture rates were high (Table 2).

During the last trapping session, $13 R$. tanezumi individuals and $17 R$. everetti individuals were trapped using kill-traps (Table $\mathrm{S} 1$ ). Seven were new $R$. tanezumi individuals, two were recaptures from a previous session and four were recaptures from the same session. One new $R$. everetti individual was captured using kill-traps, four were recaptures from a previous session and 12 were recaptures from the same session.

3.1 Rodent population responses following the short-term removal of $R$. everetti

Of the three most commonly trapped rodent species, $R$. everetti was the most abundant and $C$. mindorensis was the least abundant $\left(\mathrm{F}_{2,61.5}=49.462, \mathrm{P}<0.001\right)$ (Figure 1). Removal of $R$. everetti had no significant effect on abundance $\left(\mathrm{F}_{1,3.8}=0.017, \mathrm{P}=0.904\right)$, but the interaction between abundance and time differed between species $\left(\mathrm{F}_{10,22.4}=5.102, \mathrm{P}=0.001\right)$. In both treatment and non-treatment sites, the abundance of $R$. everetti declined from May to July and gradually 
recovered to pre-treatment levels by October, whereas the abundance of $R$. tanezumi and $C$. mindorensis showed no clear pattern, aside from a slight decline from August to October. The stages of the nearby rice crop did not influence the abundance of $R$. tanezumi in agroforest habitat $\left(\mathrm{F}_{2,20.6}=2.330, \mathrm{P}=0.144\right)$ and no other interactions were significant $(\mathrm{P}>0.05)$.

\subsection{Body size and body condition}

$R$. everetti males $(\bar{x}=210.56 \mathrm{~mm} \pm 1.73 \mathrm{SE})$ were larger than females $(\bar{x}=200.21 \mathrm{~mm} \pm 1.80 \mathrm{SE})$ $\left(\mathrm{F}_{1,214}=16.969, \mathrm{P}<0.001\right)$. The removal of $R$. everetti had no significant effect on the body size of $R$. everetti during the study $\left(\mathrm{F}_{1,214}=0.204, \mathrm{P}=0.652\right)$ and there was no significant difference between months $\left(\mathrm{F}_{5,214}=0.435, \mathrm{P}=0.824\right.$; Figure 2$)$.

Body mass corrected for body size was measured as an index of body condition. The mean body mass of adult $R$. everetti in the treatment and non-treatment sites was $2.9 \%( \pm 1.4 \mathrm{SE})$ and $4.0 \%( \pm 1.4 \mathrm{SE})$ below the mean predicted body mass in relation to their body size ${ }^{37}$, respectively. Overall, males $(-1.0 \% \pm 1.3 \mathrm{SE})$ were in better condition than females $(-6.8 \% \pm 1.5$ SE) $\left(F_{1,193}=7.208, P=0.008\right)$, but the removal of $R$. everetti had no significant effect on mean adult body condition of $R$. everetti $\left(\mathrm{F}_{1,193}=0.237, \mathrm{P}=0.627\right)$ and there was no significant difference between months $\left(\mathrm{F}_{5,193}=1.490, \mathrm{P}=0.195\right)$.

Adult $R$. tanezumi were larger in the treatment sites than in the non-treatment sites at the start and at the end of the study period $\left(\mathrm{F}_{5,115}=3.575, \mathrm{P}=0.005\right)$. The largest difference between treatments, occurred during October, when the mean adult body length of $R$. tanezumi in the treatment sites was $196.33 \mathrm{~mm}$ ( $\pm 6.17 \mathrm{SE})$, compared to a mean body length of $166.14 \mathrm{~mm}( \pm$ 6.08 SE) in the non-treatment sites. 
In the treatment and non-treatment sites, the mean body condition of adult $R$. tanezumi was $5.4 \%( \pm 1.7 \mathrm{SE})$ and $5.3 \%( \pm 1.9 \mathrm{SE})$ below the mean predicted body mass, respectively. The removal of $R$. everetti had no significant effect on mean adult body condition of $R$. tanezumi $\left(\mathrm{F}_{1,110}\right.$ $=0.977, \mathrm{P}=0.325)$ and there was no significant difference between months $\left(\mathrm{F}_{5,110}=0.419, \mathrm{P}=\right.$ $0.835)$ or $\operatorname{sex}\left(\mathrm{F}_{1,110}=1.479, \mathrm{P}=0.2226\right)$.

Adult $C$. mindorensis males $(\bar{x}=172.6 \mathrm{~mm} \pm 1.84 \mathrm{SE})$ were larger than females $(\bar{x}=161.6$ $\mathrm{mm} \pm 2.51 \mathrm{SE})$ throughout the study $\left(\mathrm{F}_{1,80}=15.636, \mathrm{P}<0.001\right)$. The mean head and body length of adult $C$. mindorensis was substantially smaller in the treatment sites before removal of $R$. everetti in May, whereas there was little difference in size between treatments following removal of $R$. everetti $\left(\mathrm{F}_{5,80}=2.461, \mathrm{P}=0.040\right)$.

There was a significant interaction between treatment, month and sex in relation to mean adult body condition of $C$. mindorensis $\left(\mathrm{F}_{3,64}=3.954, \mathrm{P}=0.012\right)$. During May, all sexes were above mean body condition for both treatments. However, from July to October, C. mindorensis females were $20-26 \%$ below the mean condition in the treatment sites, whereas in the nontreatment sites, females were above the mean condition during the same period. From June to October, mean male body condition of $C$. mindorensis fluctuated within $\pm 10 \%$ of the mean predicted body mass for both treatments, with no clear pattern.

\subsection{Sex ratio}

There was a significant difference in the proportion of females trapped between species $\left(\mathrm{F}_{2,45}=\right.$ 21.268, $\mathrm{P}<0.001)$. The sex ratio of $R$. tanezumi $(0.25 \pm 0.03 \mathrm{SE})$ and $C$. mindorensis $(0.20 \pm 0.04$ $\mathrm{SE})$ were either close to even or male biased throughout the study, whereas the sex ratio of $R$. everetti $(0.50 \pm 0.03 \mathrm{SE})$ was female biased during July and August $\left(\mathrm{F}_{10,28}=2.850, \mathrm{P}=0.014\right)$. There was a significant treatment $\mathrm{x}$ month interaction $\left(\mathrm{F}_{5,28}=5.903, \mathrm{P}=0.001\right)$. In the treatment 
sites, the sex ratio was female biased during August, following two months of $R$. everetti removal, and close to even or male biased at other times, whereas in the non-treatment sites the sex ratio was male biased throughout the study, aside from July when it was close to even .

\subsection{Reproductive parameters}

Following the removal of $R$. everetti, a lower proportion of adult $R$. everetti females were in breeding condition in the treatment sites during the post-removal period from June to October $(\bar{x}=$ $24.2 \% \pm 1.88 \mathrm{SE}, \mathrm{n}=30$ females$)$ than during the pre-removal period of May $(\bar{x}=62.5 \% \pm 2.24$ $\mathrm{SE}, \mathrm{n}=8$ females). Whereas, in the non-treatment sites, breeding condition was similar between the post-removal period $(\bar{x}=36.7 \% \pm 4.97 \mathrm{SE}, \mathrm{n}=43$ females $)$ and the pre-removal period $(\bar{x}=$ $40.0 \% \pm 8.94 \mathrm{SE}, \mathrm{n}=15$ females). Treatment and trapping period were significant predictors of R. everetti female breeding condition (Wald $\chi^{2}=7.609, \mathrm{df}=1, \mathrm{P}=0.006$; Wald $\chi^{2}=3.895, \mathrm{df}=1$, $\mathrm{P}=0.048$, respectively), but the treatment $\mathrm{x}$ trapping period interaction was not significant (Wald $\chi^{2}=2.657, \mathrm{df}=4, \mathrm{P}=0.103$ ). This is likely due to the small sample size in May.

During the post-removal period, a higher proportion of adult $R$. tanezumi females were in breeding condition in the treatment sites $(\bar{x}=77.8 \% \pm 3.56 \mathrm{SE}, \mathrm{n}=11$ females $)$ than in the nontreatment sites $(\bar{x}=26.7 \% \pm 1.83 \mathrm{SE}, \mathrm{n}=11$ females $)$. However, there was no significant difference between treatments (Wald $\chi^{2}=0.000, \mathrm{df}=1, \mathrm{P}=1.000$ ) or trapping periods (Wald $\chi^{2}=$ $0.580, \mathrm{df}=1, \mathrm{P}=0.446)$, with no significant interactions $(\mathrm{P}>0.05)$. The stage of the nearby rice crop also had no significant effect on the reproductive status of adult females (Wald $\chi^{2}=3.240, \mathrm{df}$ $=4, \mathrm{P}=0.519$. 
A higher number of adult $C$. mindorensis females were trapped in the non-treatment sites (20) than in the treatment sites (8). However, there was little difference in the proportion of adult females in breeding condition (60\% and $50 \%$, respectively). Too few adult $C$. mindorensis females were trapped for meaningful analysis.

\subsection{Microhabitat use}

In the non-treatment sites, $R$. tanezumi were more frequently trapped in trap stations with more ground vegetation cover and a similar trend was observed in the treatment sites during May (preremoval) (Figure 3). However, following the removal of $R$. everetti (June to October), R. tanezumi microhabitat selection in the treatment sites became random with respect to ground vegetation cover, as demonstrated by a significant third order interaction (Table 3 ).

Across both treatments, there was a negative association between $R$. tanezumi presence and increasing canopy cover (Table 3; Figure 3). On the other hand, there was a positive association between $R$. everetti presence and increasing canopy cover. The probability for $R$. everetti capture also increased in microhabitat with more understorey vegetation cover, but with less ground vegetation cover. However, these relationships were not significant (Table 3). The probability for $R$. everetti capture was lower in the treatment sites than in the non-treatment sites, but it declined across both treatments following the removal of $R$. everetti (Table 3).

The vegetation height above trap stations was not a significant factor influencing $R$. everetti, $R$. tanezumi or $C$. mindorensis distribution in agroforest habitat $\left(\mathrm{F}_{3,1473}=0.743, \mathrm{P}=\right.$ $0.526)$. 


\section{Discussion}

\subsection{Response of $R$. everetti following short-term control}

In agroforest habitat, mark-recapture analysis indicates that a high proportion of the resident population of $R$. everetti were removed during each removal trapping session. However, during the three-week period between trapping sessions, there was rapid immigration of $R$. everetti individuals into the removal sites, possibly in response to the increased resource availability. Similar observations have been made for other small mammals following removal, where dominant species are often the first species to respond to changes in resource levels. ${ }^{7}{ }^{43-45}$ In this case, this indicates a strong element of intraspecific competition. ${ }^{45}$ Aside from August, when the $R$. everetti sex ratio was female-biased in the treatment sites, the sex ratio did not differ between treatments, indicating that both sexes were equally prone to migration.

Even though immigration was apparent, the $R$. everetti population size in the treatment sites was lower from June to August, during the months that immediately followed removal trapping, than in May, at the start of the experiment. Coincidently, there also was a drop in the population size of $R$. everetti in the non-treatment sites during this time. This indicates that the decrease in population size may be related to indirect factors, such as climate or food. By the end of the experiment, three months after removal trapping, the $R$. everetti population size had recovered to pre-treatment levels.

At the end of the study, few $R$. everetti individuals that had not been previously caught were trapped using kill-trapping. This supports findings from Huggins closed captures models in this study and in previous studies (see Stuart ${ }^{37}$ ) showing that the capture rates of $R$. everetti using live-traps is high. In contrast, the kill-trapping results indicate that live-trapping of $R$. tanezumi 
populations only appeared to trap a subset of the population, which is consistent with previous studies. $^{37}$

\subsection{Response of the rodent community following the short-term removal of $R$. everetti}

As a consequence of rapid immigration following perturbation, $R$. everetti may have been able to maintain its competitive effect over the other rodent species. If so, then the population response of the other rodent species following the removal of $R$. everetti would be expected to be limited. In the treatment sites, the abundance of the other rodent species did not significantly increase following the removal of $R$. everetti and rodent abundance did not differ significantly between treatments. However, there were some differences in the demographic characteristics of $R$. tanezumi and C. mindorensis between treatments.

\subsubsection{Rattus tanezumi}

During the post-treatment trapping sessions, from June to October, a higher proportion of $R$. tanezumi females were in breeding condition in the treatment sites than in the non-treatment sites, which suggests that $R$. everetti has a negative effect on female $R$. tanezumi reproductive activity in the non-treatment sites. However, due to the low numbers of $R$. tanezumi females captured, there was no significant difference between treatments.

Adult $R$. tanezumi were substantially larger in the treatment sites than in the non-treatment sites at the end of the study period, which suggests that three months after removal trapping, $R$. tanezumi were on average older in the treatment sites. ${ }^{46}$ This may be indicative of higher survival rates, or it may be a consequence of lower recruitment rates. It is unlikely to be the latter as the proportion of females in breeding condition was higher in the treatment sites. Unfortunately, $R$. 
tanezumi recapture rates were too low for in-depth survival analysis using mark recapture methods. There also was no apparent difference in individual fitness between treatments, as assessed by body condition.

\subsubsection{Chrotomys mindorensis}

There is no evidence of direct competition between $C$. mindorensis and $R$. everetti. On the contrary, C. mindorensis females had below-average fitness values in the removal sites following the removal of $R$. everetti. This may the result of an indirect interaction, for example, if there was reduced competitive pressure on $R$. tanezumi by $R$. everetti in the treatment sites, this may have resulted in increased competition between $R$. tanezumi and C. mindorensis. Further studies, ideally over a long-term, are required to understand the importance and nature of such indirect effects. ${ }^{47}$

\subsection{Microhabitat use}

Following the removal of $R$. everetti individuals, the microhabitat selection of $R$. tanezumi, as measured through trap occupancy, shifted from selection towards microhabitat with more ground vegetation cover to that of no particular selection pattern, indicating that there was possibly reduced competitive pressure by $R$. everetti. $R$. everetti removal had no significant effect on $R$. everetti abundance, thus it is unlikely that exploitation competition between $R$. tanezumi and $R$. everetti for food patches is occurring. It seems more likely that there may be interference competition between these two species, with the larger $R$. everetti competitively dominant over $R$. tanezumi. In support of this hypothesis, previous studies on rodents have shown that female territorial defense increases during the breeding season. ${ }^{48,49}$ In this study, the lower proportion of $R$. everetti females in breeding condition following removal sessions suggest that these recent 
immigrants were perhaps less territorial than those already established in the more stable nontreatment sites.

Irrespective of the treatment, there was a contrast in the use of canopy cover by $R$. tanezumi and $R$. everetti. $R$. tanezumi selected microhabitat with less canopy cover, which one would associate with severely disturbed habitat patches that have few trees, whereas, $R$. everetti selected microhabitat with a more dense canopy. These results are consistent with the results from a radio tracking study by Stuart et al. ${ }^{50}$, which revealed that $R$. tanezumi prefer to nest in edge or open habitat with low canopy cover. Another trapping study in the same geographical location caught few $R$. everetti in the more disturbed lowland coconut groves that have a relatively low canopy cover due to low tree species diversity, whereas trap success was higher in the agroforest and forest habitats that had denser canopy. ${ }^{17,25}$ The differential use of microhabitat may help to explain how both of these generalist rodent species are able to co-exist in moderately disturbed agroforest ecosystems that have a heterogeneous vegetation structure.

Ong and Rickart ${ }^{9}$ postulated that practices that minimise habitat disturbance on crop margins and encourage the regeneration of second-growth forest would increase native small mammal diversity, and subsequently provide effective management against non-native pest rodents when used in conjunction with traditional control measures. Although, our study does not provide clear evidence for competition between native and invasive rodent species, the results from our study and from previous studies do indicate that the practices that minimise habitat disturbance, resulting in an increase in canopy cover, would reduce the habitat suitability for $R$. tanezumi, as well as increase the habitat suitability for $R$. everetti and other native rodent species. ${ }^{9}$, 14, 15 We hypothesise that in this type of vegetation structure there would be a decrease in the abundance of $R$. tanezumi, and a concomitant reduction in rodent losses to rice and coconut crops. 


\section{Conclusions}

In response to the increased availability of resources following perturbation, the rapid immigration of $R$. everetti into vacated habitat indicates that this species would be able to recover from the nontarget effects of short-term lethal rodent control in and around agroforest habitat. The close proximity of the removal sites to secondary lowland forest (within $200-500 \mathrm{~m}$ ) may have aided the rapid immigration of this species into the treatment sites. The demographic characteristics of this species do not differ significantly between agroforest and forest habitat, ${ }^{37}$ even so, the complexity of the ecosystem and the level of disturbance in adjacent areas should be considered when applying lethal rodent control measures in and around agroforest habitat.

Due to the rapid immigration of $R$. everetti following removal, we were not able to fully investigate the competitive interaction between $R$. everetti and $R$. tanezumi in an agroforest habitat. To further explore this relationship, a press experiment should be designed to maintain a predetermined perturbation level by increasing the removal area with more frequent removal trapping, ${ }^{28}$ by adding inter-session trapping, ${ }^{7}$ or by continuous removal trapping throughout the removal period.

The difference in the use of vegetation cover between $R$. everetti and $R$. tanezumi provides a potential opportunity to manage the negative impact of an invasive pest species on agricultural crops by minimising disturbance and allowing more natural habitat to regenerate within agroforest, particularly around crop margins. We would expect this to be beneficial to other native flora and fauna, as well as favour the native rodent $R$. everetti over the invasive rodent $R$. tanezumi. This could provide a novel approach to species conservation in agro-ecosystems that may also benefit small-scale farmers; providing a balance between human needs and conservation 
that is often required to protect fragile ecosystems on a landscape scale. ${ }^{51}$ Replicated habitat manipulation studies are now needed to test this approach in the field.

\section{Acknowledgements}

We thank Dr. L. Sebastian, Dr. R. Joshi and the Crop Protection staff from the Department of Agriculture-Philippine Rice Research Institute (DA-PhilRice) for their support in setting up the project. AMS thanks R. Gadayan for his dedicated assistance in the field; P. Leander, O. Diesta and A. Novicio for helping to establish contacts within the local communities; B. Mina and M. Millan for their assistance in the acquisition of scientific permits; and the local farmers for permitting to trap on their land. We gratefully acknowledge Prof. C. Krebs for advice on experimental design; and Dr. P. Baker for his statistical advice. We thank anonymous reviewers for their helpful comments that improved the manuscript. Fieldwork was approved by the municipal governments of Baler and San Luis and scientific permits were granted by the

Philippine Department of Environment and Natural Resources (07-13488/062507). The project was supported by funding to the International Rice Research Institute provided by the Swiss Agency for Development and Cooperation for the Irrigated Rice Research Consortium.

\section{References}

1. Amori $\mathrm{G}$ and Gippoliti S, Identifing priority ecoregions for rodent conservation at the genus level. Oryx; 35:158-165 (2001).

This article is protected by copyright. All rights reserved. 
2. Amori G, Gippoliti S and Helgen KM, Diversity, distribution, and conservation of endemic island rodents. Quaternary International; 182:6-15 (2008).

3. Corlett R, Invasive aliens on tropical East Asian islands. Biodiversity and Conservation; 19:411-423 (2010).

4. Harper GA and Bunbury N, Invasive rats on tropical islands: Their population biology and impacts on native species. Global Ecology and Conservation; 3:607-627 (2015).

5. Stokes VL, Banks PB, Pech RP and Spratt DM, Competition in an invaded rodent community reveals black rats as a threat to native bush rats in littoral rainforest of southeastern Australia. J Appl Ecol; 46:1239-1247 (2009).

6. Courchamp F, Chapuis JL and Pascal M, Mammal invaders on islands: impact, control and control impact. Biological Reviews; 78:347-383 (2003).

7. Harris DB and Macdonald DW, Interference competition between introduced black rats and endemic Galapagos rice rats. Ecology; 88:2330-2344 (2007).

8. Banks PB and Hughes NK, A review of the evidence for potential impacts of black rats (Rattus rattus) on wildlife and humans in Australia. Wildlife Research; 39:78-88 (2012). Ong PS and Rickart EA, Ecology of native and pest rodents in the Philippines, in Philippine rats: Ecology and management, ed. by Joshi RC, Singleton GR and Sebastian LS, Philippine Rice Research Institute, Science City of Muñoz, Nueva Ecija, pp. 101-116 (2008).

10. Hoque MM and Sanchez FF, Development of rodent management in the Philippines from 1968 to 1988, in Philippine rats: Ecology and management, ed. by Singleton GR, Joshi RC and Sebastian LS, Philippine Rice Research Institute, Science City of Muñoz, Nueva Ecija, pp. 9-24 (2008). 
11. Banks PB and Smith HM, The ecological impacts of commensal species: black rats, Rattus rattus, at the urban-bushland interface. Wildlife Research; 42:86-97 (2015).

12. Heaney LR, Balete DS, Dolar ML, Alcala AC, Dans ATL, Gonzales PC, Ingle NR, Lepiten MV, Oliver WLR, Ong PS, Rickart EA, Tabaranza BRJ and Utzurrum RCB, A synopsis of the mammalian fauna of the Philippine Islands. Fieldiana Zoology new series; 88:1-61. (1998).

13. Stuart AM, Prescott CV, Singleton GR, Joshi RC and Sebastian LS, The rodent species of the Ifugao Rice Terraces, Philippines - Target or non-target species for management? International Journal of Pest Management; 53:139-146 (2007).

14. Rickart EA, Balete DS and Heaney LR, Habitat disturbance and the ecology of small mammals in the Philippines Journal of Environmental Science and Management 10:34-41 (2007).

15. Rickart EA, Balete DS, Rowe RJ and Heaney LR, Mammals of the northern Philippines: tolerance for habitat disturbance and resistance to invasive species in an endemic insular fauna. Diversity and Distributions; 17:530-541 (2011).

16. Reginaldo AA and de Guia APO, Species richness and patterns of occurrence of small non-flying mammals of Mt. Sto Tomas, Luzon Island, Philippines. Philippine Science Letters; 7:37-44 (2014).

17. Stuart AM, Prescott CV, Singleton GR and Joshi RC, Rodent diversity in the lowland agro-ecosystems of the Sierra Madre Biodiversity Corridor, Philippines. Sylvatrop; 18:111126 (2008).

18. Joshi RC, Gergon EB, Aplin KP, Singleton GR, Martin AR, Cabigat JC, Cayong A, Desamero NV and Sebastian LS, Rodents and other small mammals in Banaue and Hungduan rice terraces, Philippines. International Rice Research Notes; 29:44-46 (2004). 
19. Heaney LR, Balete DS, Gee GA, Lepiten-Tabao MV, Rickart EA and Tabaranza BR, Preliminary report on the mammals of Balbalasang, Kalinga Province, Luzon. Sylvatrop; 13:59-72 (2005).

20. Banks PB, Goumas M, Heavener SJ, Dickman CR, Stokes VL, Hughes NK, Pech RP, Byrom A, Cleary GP, Weerakoon M, Smith HC and Bytheway JP. Using native rodents to control pest rodents. In Rodent population ecology, behavior and management in the North and South Konnevesi Research Station, University of Jyväskylä, Finland 21-24 February 2012, ed. by Ylonen H and Singleton G, pp. 13 (2012).

21. Taylor PJ, Downs S, Monadjem A, Eiseb SJ, Mulungu LS, Massawe AW, Mahlaba TA, Kirsten F, Von Maltitz E, Malebane P, Makundi RH, Lamb J and Belmain SR, Experimental treatment-control studies of ecologically based rodent management in Africa: balancing conservation and pest management. Wildlife Research; 39:51-61 (2012).

22. Heaney LR, Heideman PD, Rickart EA, Utzurrum RB and Klompen JSH, Elevational zonation of Mammals in the Central Philippines. Journal of Tropical Ecology; 5:259-280 (1989).

23. Rickart EA and Heaney LR, A new species of Chrotomys (Rodentia, Muridae) from Luzon Island, Philippines. Proceedings of the Biological Society of Washington; 104:387-398 (1991).

24. Balete DS, Heaney LR, Josefa Veluz M and Rickart EA, Diversity patterns of small mammals in the Zambales Mts., Luzon, Philippines. Mammalian Biology - Zeitschrift fur Saugetierkunde; 74:456-466 (2009).

25. Stuart AM, Singleton GR and Prescott CV, The population ecology of the Asian house rat (Rattus tanezumi) in complex lowland agro-ecosystems in the Philippines. Wildlife Research; 42: 165-175 (2015) 
26. Singleton GR. Impacts of rodents on Rice Production in Asia. Discussion Paper. In No 45. International Rice Research Institute: Philippines, pp. 30 (2003).

27. Stuart AM, Prescott CV, Singleton GR and Joshi RC, Knowledge, attitudes and practices of farmers on rodent pests and their management in the lowlands of the Sierra Madre Biodiversity Corridor, Philippines. Crop Protection; 30:147-154 (2011).

28. Bender EA, Case TJ and Gilpin ME, Perturbation Experiments in Community Ecology: Theory and Practice. Ecology; 65:1-13 (1984).

29. Sinclair ARE, Fryxell JM and Caughley G, Wildlife Ecology, Conservation and Management. Second Edition. Blackwell Publishing, Oxford, (2006).

30. Birch LC, The Meanings of Competition. The American Naturalist; 91:5-18 (1957).

31. Rosenzweig ML, A Theory of Habitat Selection. Ecology; 62:327-335 (1981).

32. Manly BF, McDonald L, Thomas D, McDonald TL and Erickson WP, Resource Selection by Animals: Statistical Design and Analysis for Field Studies. Kluwer Academic Publishers, Dordrecht, The Netherlands, (2002).

33. Krebs CJ, Ecological Methodology. Second Edition. Addison-Welsey Educational Publishers, Menlo Park, CA, (1999).

34. Aplin K, Brown P, Jacob J, Krebs C and Singleton G, Field methods for rodent studies in Asia and the Indo-Pacific. ACIAR monograph No. 100, Canberra, (2003).

35. White GC and Burnham KP, Program MARK: survival estimation from populations of marked animals. Bird Study; 46:120-139 (1999).

36. Pledger S, Unified maximum likelihood estimates for closed capture-recapture models using mixtures. Biometrics; 56:434-442 (2000).

This article is protected by copyright. All rights reserved. 
37. Stuart AM, Rodent ecology and management in the complex lowland agro-ecosystems of the Sierra Madre Biodiversity Corridor, Philippines. PhD Thesis, University of Reading (2009).

38. Alfonso PJ, Fieldler LA and Sumangil JP, Rodent ecology, population dynamics and behaviour, in Rodent Biology and Control (with special reference to the Philippines), ed. by Sanchez FF and Benigno EA, The National Crop Protection Center, Los Baños, Philippines, pp. 25-47 (1985).

39. Wauters LA, Vermeulen M, Van Dongen S, Bertolino S, Molinari A, Tosi G and Matthysen E, Effects of spatio-temporal variation in food supply on red squirrel Sciurus vulgaris body size and body mass and its consequences for some fitness components. Ecography; 30:51-65 (2007).

40. Krebs CJ and Singleton GR, Indexes of condition for small mammals. Australian Journal of Zoology; 41:317-323 (1993).

41. Krzanowski WJ, Statistical Principles and Techniques in Scientific and Social Research. Oxford University Press, Oxford (2007).

42. Field A, Discovering Statistics Using SPSS. Second edition SAGE Publications, London (2005).

43. Gliwicz J, Competitive interactions within a forest rodent community in central Poland. Oikos; 37:353-362 (1981).

44. Busch M and Kravetz FO, Competitive interactions among rodents (Akodon-Azarae, Calomys-Laucha, Calomys-Musculinus and Oligoryzomys-Flavescens) in a 2-habitat system. 2. Effect of species removal. Mammalia; 56:541-554 (1992).

45. Schroder G and Rosenzweig M, Perturbation analysis of competition and overlap in habitat utilization between Dipodomys ordii and Dipodomys merriami. Oecologia; 19:9-28 (1975). 
46. Ferrer LS, A laboratory study on juvenile growth of the common ricefield rat. M.S. Thesis, University of the Philippines at Los Banos, Philippines, (1975).

47. Heske EJ, Brown JH and Mistry S, Long-term experimental-study of a Chihuahuan desert rodent community - 13 years if competition. Ecology; 75:438-445 (1994).

48. Wolff JO, Density-dependence and the socioecology of space use in rodents, in Rats, mice and people: Rodent biology and management, ed. by Singleton GR, Hinds LA, Krebs CJ and Spratt DM, Australian Centre for International Agricultural Research, Canberra, pp. 123-130 (2003).

49. Maestripieri D, Functional-aspects of maternal aggression in mammals. Canadian Journal of Zoology-Revue Canadienne De Zoologie; 70:1069-1077 (1992).

50. Stuart AM, Prescott CV and Singleton GR, Natal nest locations of the Asian house rat (Rattus tanezumi) in lowland rice-coconut cropping systems: a coconut penthouse or rice bunds with water frontage? Wildlife Research; 39:496-502 (2012).

51. Posa MRC, Diesmos AC, Sodhi NS and Brooks TM, Hope for Threatened Tropical Biodiversity: Lessons from the Philippines. Bioscience; 58:231-240 (2008). 


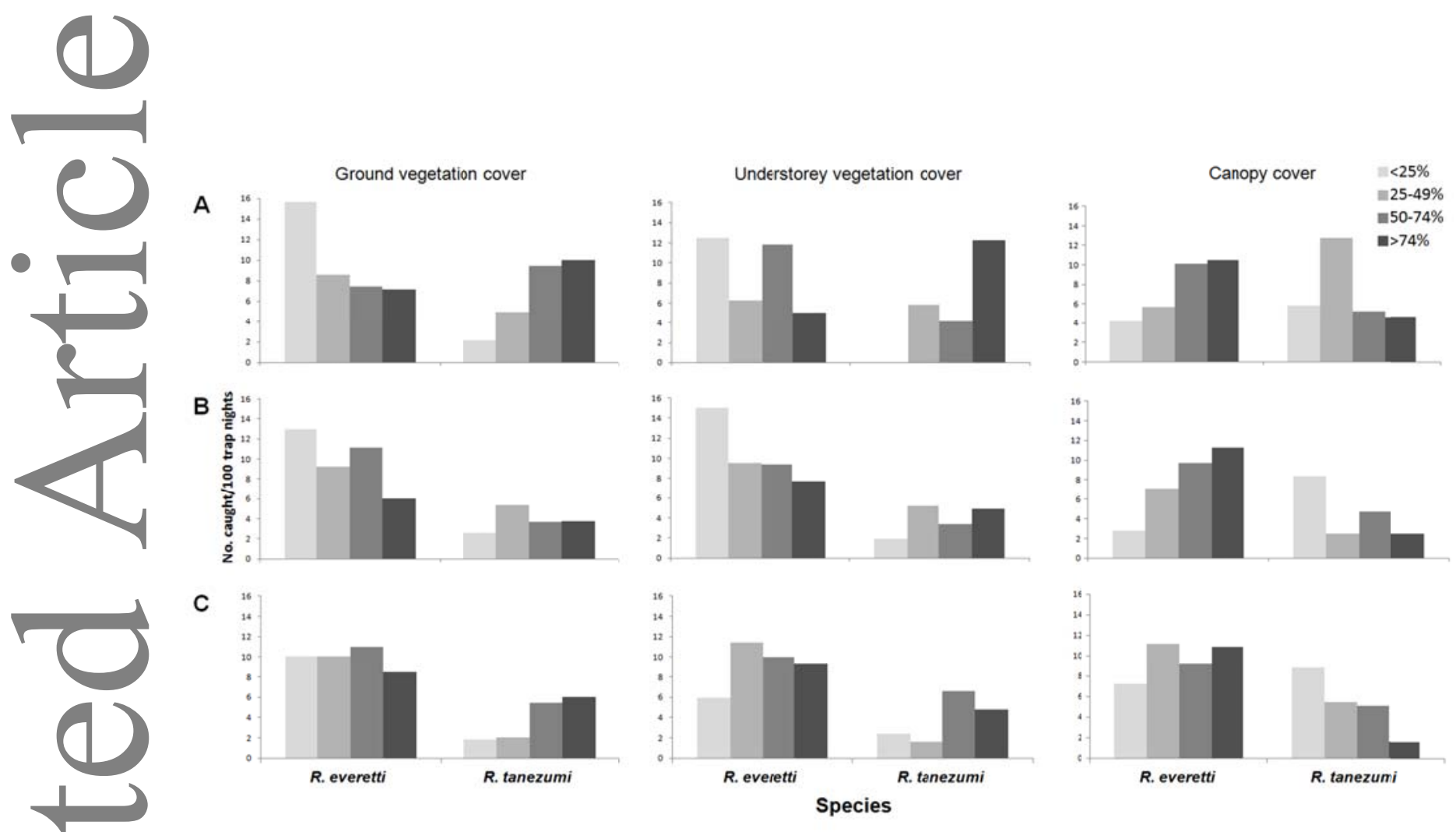

Figure 3. The number of Rattus everetti and Rattus tanezumi trapped in agroforest habitat proportional to the number of available trap stations with an understorey, ground and canopy vegetation cover of $<25 \%, 25-49 \%, 50-74 \%$, and $>74 \%$ in a) treatment sites before $R$. everetti removal during May, b) treatment sites following $R$. everetti removal from June to October, and c) non-treatment sites with no removal from June to October. 
Table 1 The number of $R$. everetti individuals trapped and recaptured during removal sessions in treatment sites $\mathrm{T} 1$ and $\mathrm{T} 2$. All $R$. everetti individuals trapped on day 1 were released and all those trapped on days 2-4 were removed.

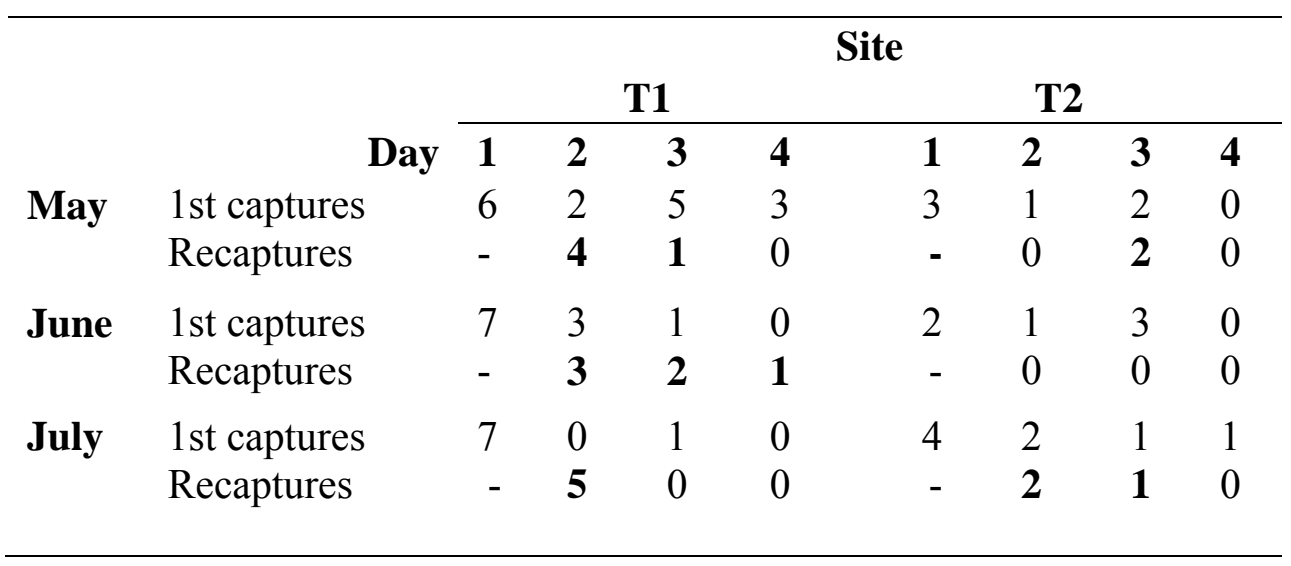

This article is protected by copyright. All rights reserved. 
Table 2 Model averaged estimates of the total Rattus everetti abundance (N-hat) and the total number of individuals caught $(\mathrm{Mt}+1)$ per month across two treatment sites and acrosstwo nontreatment sites in agroforest habitat.

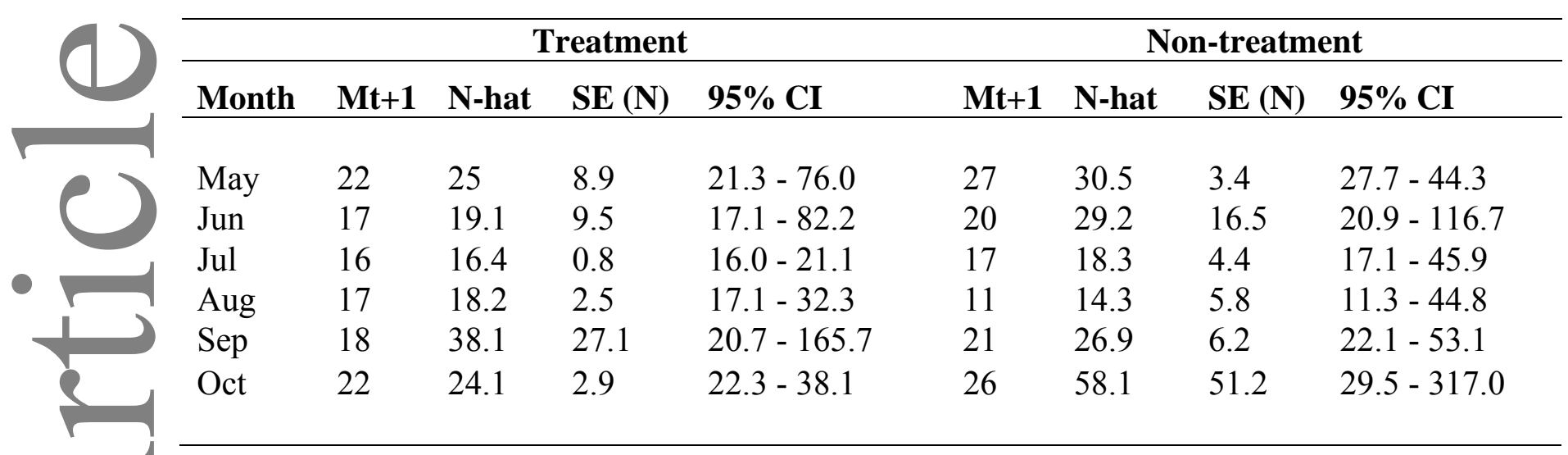

This article is protected by copyright. All rights reserved. 
Table 3 A logistic regression model of the effect of microhabitat vegetation cover and treatment (removal of Rattus everetti) on trap occupancy by Rattus tanezumi and Rattus everetti over six trapping sessions.

\begin{tabular}{|c|c|c|c|c|c|c|c|c|c|c|c|c|}
\hline \multirow[b]{2}{*}{ Variable } & \multicolumn{2}{|c|}{ Rattus everetti } & \multicolumn{10}{|c|}{ Rattus tanezumi } \\
\hline & $b$ & S.E. & Wald $\chi^{2}$ & $d f$ & $p$ & $\operatorname{Exp}(b)$ & $\boldsymbol{b}$ & S.E. & Wald $\chi^{2}$ & $d f$ & $p$ & $\operatorname{Exp}(b)$ \\
\hline Constant & -1.85 & 0.46 & 16.23 & 1 & $<0.001$ & 0.158 & -2.80 & 0.60 & 21.45 & 1 & $<0.001$ & 0.061 \\
\hline Site & & & 6.89 & 3 & 0.075 & & & & 25.48 & 3 & $<0.001$ & \\
\hline Month & & & 20.61 & 5 & 0.001 & & & & 26.06 & 5 & $<0.001$ & \\
\hline Jun & -0.56 & 0.24 & 5.24 & 1 & 0.022 & 0.572 & -0.40 & 0.42 & 0.87 & 1 & 0.351 & 0.673 \\
\hline Jul & -0.75 & 0.26 & 8.26 & 1 & 0.004 & 0.473 & -0.01 & 0.36 & 0.00 & 1 & 0.968 & 0.986 \\
\hline Aug & -0.59 & 0.24 & 6.06 & 1 & 0.014 & 0.552 & 1.00 & 0.30 & 10.88 & 1 & 0.001 & 2.724 \\
\hline Sep & -0.32 & 0.23 & 1.92 & 1 & 0.166 & 0.725 & -0.27 & 0.40 & 0.43 & 1 & 0.511 & 0.766 \\
\hline Oct & 0.11 & 0.22 & 0.27 & 1 & 0.601 & 1.119 & 0.21 & 0.35 & 0.35 & 1 & 0.554 & 1.229 \\
\hline Treatment & -0.35 & 0.16 & 5.00 & 1 & 0.025 & 0.705 & -0.30 & 0.22 & 1.98 & 1 & 0.159 & 0.7381 \\
\hline Canopy cover & 0.18 & 0.08 & 5.35 & 1 & 0.021 & 1.196 & -0.24 & 0.10 & 5.45 & 1 & 0.020 & 0.790 \\
\hline Ground cover & -0.15 & 0.08 & 3.56 & 1 & 0.059 & 0.865 & 0.23 & 0.10 & 5.34 & 1 & 0.021 & 1.265 \\
\hline Understorey cover & 0.17 & 0.09 & 3.32 & 1 & 0.068 & 1.182 & 0.14 & 0.11 & 1.79 & 1 & 0.181 & 1.155 \\
\hline Month*treatment* ground. & & & 5.08 & 5 & 0.406 & & & & 19.11 & 5 & 0.002 & \\
\hline Jun*treatment*ground. & -0.20 & 0.25 & 0.61 & 1 & 0.437 & 0.821 & -0.41 & 0.21 & 3.83 & 1 & 0.050 & 0.666 \\
\hline Jul*treatment*ground. & -0.03 & 0.22 & 0.01 & 1 & 0.903 & 0.974 & -0.38 & 0.16 & 5.37 & 1 & 0.021 & 0.686 \\
\hline Aug*treatment*ground. & 0.34 & 0.21 & 2.60 & 1 & 0.107 & 1.402 & -0.55 & 0.13 & 17.16 & 1 & $<0.001$ & 0.575 \\
\hline Sep*treatment*ground. & 0.05 & 0.18 & 0.08 & 1 & 0.774 & 1.054 & -0.25 & 0.16 & 2.52 & 1 & 0.113 & 0.780 \\
\hline Oct*treatment*ground. & -0.15 & 0.16 & 0.83 & 1 & 0.361 & 0.863 & -0.44 & 0.16 & 7.39 & 1 & 0.007 & 0.644 \\
\hline Month*treatment*under. & & & 5.59 & 5 & 0.348 & & & & & & & \\
\hline Jun*treatment*under. & 0.21 & 0.21 & 1.01 & 1 & 0.314 & 1.238 & & & & & & \\
\hline Jul*treatment*under. & 0.17 & 0.20 & 0.74 & 1 & 0.391 & 1.185 & & & & & & \\
\hline Aug*treatment*under. & -0.16 & 0.24 & 0.45 & 1 & 0.502 & 0.853 & & & & & & \\
\hline Sep*treatment*under. & 0.08 & 0.20 & 0.16 & 1 & 0.690 & 1.081 & & & & & & \\
\hline Oct*treatment*under. & 0.30 & 0.16 & 3.36 & 1 & 0.067 & 1.347 & & & & & & \\
\hline
\end{tabular}

